\title{
Wage Premium in the Industrial Sector of the Spanish Economy: Empirical Evidence
}

\author{
Rosario Sánchez - Amparo Urbano - Angel Ortí
}

Abstract. This paper presents evidence that firm-level productivity increases when the relative wage rises, or the level of unemployment rises. Both facts are consistent with the efficiency wage model. Moreover, there is support for the idea that an increase in the sector's wage with respect to the previous year also increases productivity. We obtain the empirical evidence through a double-hurdle model. We use this estimation technique because it can be established that the differences in productivity between sectors could be explained by differences in effort. It means that some of the industrial sectors of the Spanish economy may pay wage premia while others do not. We also test this implication through panel data.

\section{Introduction}

The efficiency wage models are all based on a convincing and coherent explanation of why firms may find it unprofitable to cut wages in the presence of involuntary unemployment. According to this hypothesis, labour productivity depends on the real wage paid by the firm. These approaches identify four benefits of higher wage payments: reduced avoidance of work by employees due to a higher cost of job loss, lower turnover, improvement in the job quality of job applicants,

Rosario Sánchez, Amparo Urbano, Angel Ortí, Departamento de Analisis Económico, Facultad de C. Económicas y Empresariales, Blasco Ibañez 32, E-46010 Valencia, Spain.

We would like to thank the Fundación Empresa Pública for the data source, especially J. C. Fariñas and C. Martín. Also we would like to thank J. Jamandreu, J. M. Labeaga, the participants of the $20^{\text {th }}$ EARIE conference and those of the fifth EALE conference for helpful comments.

Received on November 4, 1993 and approved by the Editorial Board on February 21, 1995. 
and improved morale. In this paper, we focus on the predictions of the shirking and the sociological models. The novelty that our work incorporates is to estimate the effect of the wage premium on productivity throughout a model of censored dependent variable and panel data.

The traditional shirking model is based on the imperfect information that firms have concerning the effort of their employees. Monitoring individual performance is assumed to be impossible, or very costly, and the punishment for low performance is limited by legal constraints. As an incentive for workers to work instead of shirking, firms may find it profitable to raise wages. This attitude increases the cost of job loss for the worker in two ways. First, because this wage is higher than the wage paid by other firms. Second, it is above the market-clearing level and will thus generate involuntary unemployment and also diminish his expected outside earnings. In the simplest version, according to Shapiro and Stiglitz (1984) workers and firms are assumed to be homogeneous and, as firms are identical, they would all find it profitable to raise wages. Relative wages will stay constant, and only unemployment will act as a discipline device, increasing the cost of job loss.

The sociological model considers that workers' effort depends on whether they believe their employer is treating them fairly. If the wage is perceived as just, workers' morale will improve, their feelings of loyalty will increase, and so will their productivity. Especially important perhaps, are recent models that attempt to formalize the essence of actual wage setting in which interpersonal comparisons among workers seem to override other considerations (Akerlof, 1982). These models stress the productivity consequences of worker morale, wage norms, and subjective concepts of fairness among workers. Maintenance of such norms is thought to support the important subjective beliefs of workers that they are being treated fairly. Workers paid noticeably less than what they think they deserve are thought to be much less productive.

A whole family of models have been built around this basic framework by varying what is assumed measurable, at what cost, and the payment schedules that are feasible. Krueger and Summers (1986) estimate standard wage equations using cross-section data on individuals. They used data from the US Current Population Surveys for 1974, 1979 and 1984. The industry and occupation variables were found to be relatively important explanatory variables for variation in earnings. Murphy and Topel (1987) also use longitudinal data, and produce different results from those obtained using cross-section data. Gibbons and Katz (1989) point out that the previous evidence based on 
longitudinal data only deals with the objection that inter-industry wage differential proxy for unobserved ability differences if each worker's productive ability is valued equally in different industries. In the Gibbons and Katz model, information about ability is imperfect ex-ante, but improves ex-post, i.e. the market observes a noisy signal about each worker's ability at the time of hiring, but more is learnt through actual subsequent productivity. The workers who are subsequently discovered to belong to the wrong industry then move.

In this paper, we attempt to test the efficiency wage model by examining some of its predictions for the determinants of a firm's productivity. Efficiency wage models require that changes in unemployment increase a firm's productivity. This is in contrast to a neoclassical production function, where outside unemployment plays no such role. Similarly, if workers are homogeneous, differences in the relative wage paid should not, in a standard neoclassical model, affect the firm's output. We also find some evidence for a modified efficiency wage model where workers do not merely compare their wage with outside opportunities, but also allow their comparison standard to rise with past achievements.

In the short run, we estimate a function which reflects the effect of the wage premium paid by the sector on the average product of labour. The firms cannot observe the effort of each worker; they only know the average productivity of labour. In our model, we assume that average productivity of labour depends on effort and capital stock by worker.

The effort is unobserved and, for this reason, we use a censored dependent variable model to predict the existence of this wage premium. We assume that if the industrial sectors of the Spanish economy pay efficiency wages, they will have a positive labour-augmenting production function. The factor of augmentation, in this context, is the effort. This paper presents a new possibility for testing the implications of this kind of model.

\section{The theoretical approach}

\subsection{The basic framework}

The basic framework in an efficiency wage model starts by considering an economy with identical and perfectly competitive firms, each firm having a short-run production function:

$$
Y=f[e(w) L]
$$


where $L$ is the number of employees, $e$ is the effort per worker, and $w$ is the real wage. A profit-maximizing firm can hire all the labour it wants at the wages it chooses to offer. The firm will choose the wage to maximize profits. The profit function is:

$$
\Pi=f[e(w) L, K]-w L-r K
$$

The F.O.C. for maximization are:

$$
\begin{aligned}
& \frac{\delta \Pi}{\delta L}=f_{1} e-w=0 \\
& \frac{\delta \Pi}{\delta w}=f_{1} \frac{\delta e}{\delta w} L-L=0 \\
& \frac{\delta \Pi}{\delta K}=f_{2}-r=0
\end{aligned}
$$

dividing [4] by [3] we obtain Solow's condition. ${ }^{1}$ The firm will hire labour until the point where the effective marginal productivity of labour $\left(f_{1} e\right)$ is equal to the wage, and, for this, will offer the wage that fulfill Solow's condition.

The relationship between effort and real wage has to be positive in an efficiency wage model. We can assume an effort function as it appears in Figure 1 . We can suppose that $w_{0}$ is the minimum real wage, and $w^{*}$ is the profit maximizing wage; at this point, the elasticity of the effort with respect to the wage is unity. The effort function is convex for values below $w^{*}$, which implies that effort is increasing more quickly than wages and that there is a strong wage capture. In the concave area, for values above $w^{*}$, the effort increases less than wages and thus there is a weak wage capture. No firm will be situated in the convex region.

We are assuming that the industrial sectors of the Spanish economy are interested in the effectiveness of labour more than in the number of workers they hire, and are thus willing to pay above the opportunity wage of their labour force. Even if all the sectors pay efficiency wages, nothing guarantees that would they pay the same equilibrium wage. Competition should weed out substantially different costs per efficient unit, forcing similar and competitive firms into a common type of techno-institutional efficiency that minimizes costs per efficiency unit. In this way, a cross-section of competing firms should satisfy Solow's condition. In Figure 2, we observe that the tangent that minimizes costs per efficient unit for different firms all lie on the same ray from the 
Figure 1. The effort function

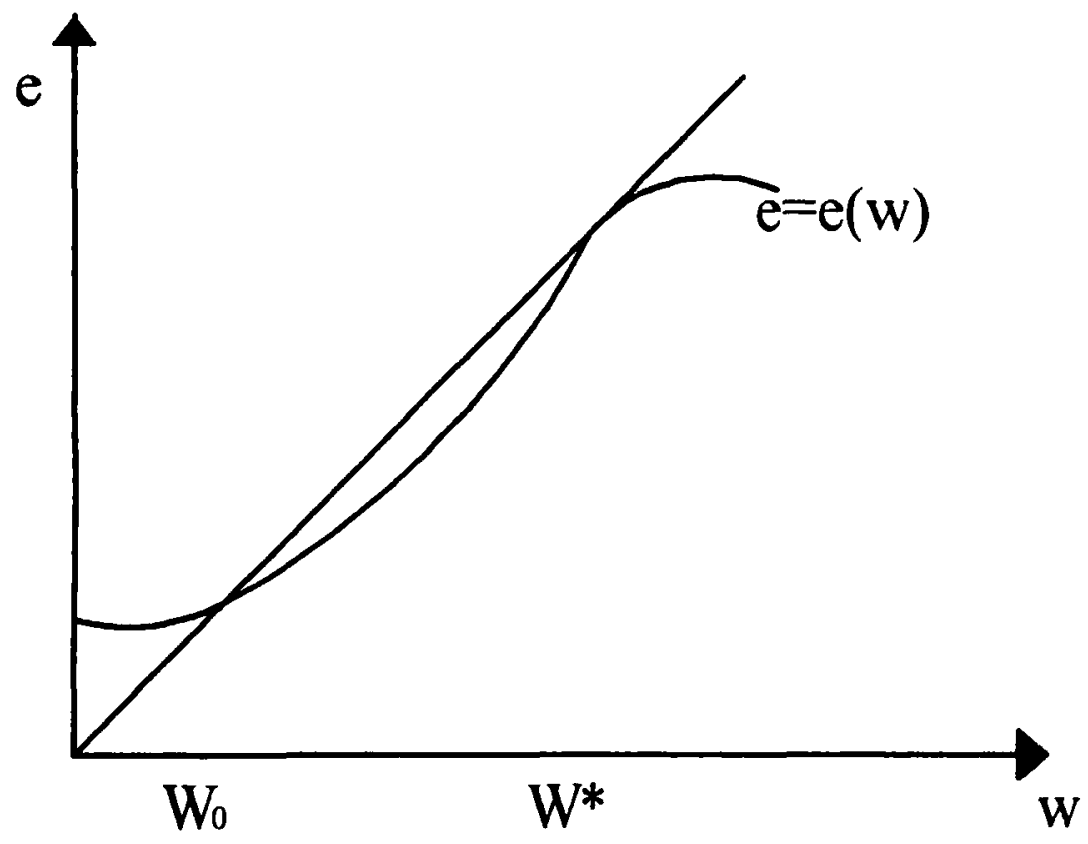

origin. This would seem to be more likely for competing firms facing similar technological and institutional constraints.

\subsection{The average productivity of labour}

Our main goal is to estimate the existence of wage premium for the industrial sector of the Spanish economy. To this end, we first have to derive the conditions that allows us to apply such a model. The firms cannot observe the effort of each worker, but they know the average productivity of their labour force. In the short run, we assume that the average productivity of labour depends on:

$$
\frac{Y}{L}=g(e, K / L)
$$

where $e$ is the effort and $K / L$ is the capital stock by worker. Also, the level of effort in each firm will depend on the real wage, $w$, paid:

$$
e=e(w)
$$


Figure 2. Same cost per efficient unit

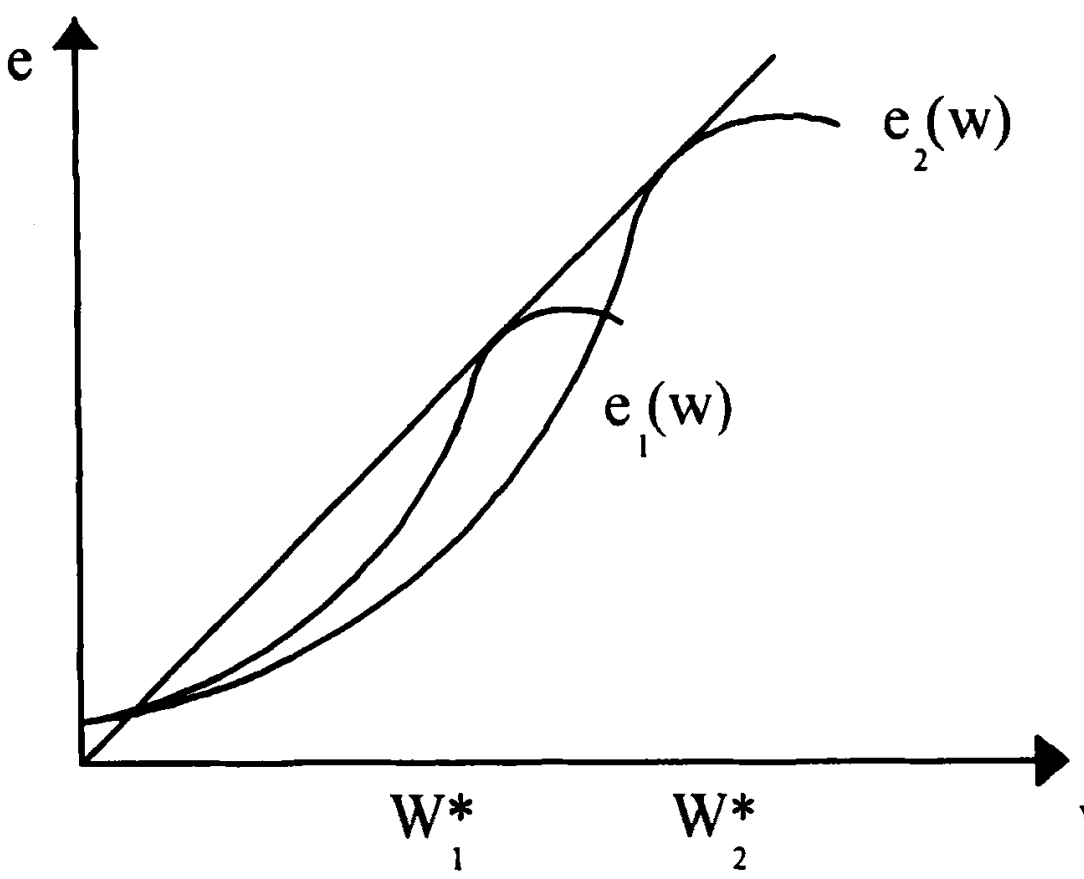

Differentiating [6] we obtain:

$$
\mathrm{d}(\bar{Y} / L)=g_{1} \frac{\delta e}{\delta w} \mathrm{~d} w+g_{2} \mathrm{~d}(\bar{K} / L)
$$

operating in [8] and substituting $\delta e / \delta w$ by $e^{\prime}$ we have:

$$
\bar{Y} / L=-g_{1} e^{\prime} \frac{\mathrm{d} w}{\mathrm{~d} L} L+g_{2} \frac{\bar{K}}{L}
$$

If we multiply the first term of the right-hand side of [9] by $(e / w)(w / e)$ we can write:

$$
\bar{Y} / L=g_{1} \frac{\varepsilon_{w}{ }^{e}}{\varepsilon_{w}{ }^{l}} e+g_{2} \frac{\bar{K}}{L}
$$

where $g_{1}$ is the first derivative of the average product of labour with respect to effort, $\varepsilon_{w}{ }^{e}$ is the elasticity of the effort with respect to the 
wage, $\varepsilon_{\omega}{ }^{L}$ is the elasticity of the labour demand with respect to the wage, and $g_{2}$ is the first derivative of the average productivity of labour with respect to the capital stock by worker.

\section{Data, methodology and estimation}

Our basic data source is published in the Spanish Industrial Enquiry (SIE) for 89 sectors of the economy, carried out by the National Institute of Statistics (INE) and Fundación Empresa Pública. The precise data definitions are discussed in the Data Appendix. For estimation we use 81 sectors.

Our main goal is to estimate the existence of wage premia, which can be done by a cross-section estimation. We group sectors with the same ratio $(K / L)$ in order to eliminate the influence of this variable on the average productivity of labour. If one sector, for example $i$, has an average productivity of labour above the average of its group, it is because the level of effort of its labour force is also bigger.

We group the sectors by two methods. The first tries to get the small deviation about the capital stock by the worker's ratio. With the second, we are more interested in grouping the sectors around the same kind of activity. In this case, the deviations about capital stock are bigger but we can obtain the same group of sector for all the years. The second case also allows us to estimate through panel data.

Generally, we suppose the average productivity of labour of the sector $i$ depends on:

$$
[Y / L]_{i}=g\left[e_{i},(\bar{K} / L)_{i}\right]
$$

where $[Y / L]_{i}$ is the average productivity of labour of the sector $i, e_{i}$ is the level of effort and $(\bar{K} / L)_{i}$ is the capital by worker. Defining the effort as a function that depends on the variables:

$$
e_{i}=e\left(w_{i}, v_{w r a n d}, \text { pempd }_{i}, \text { vempd }_{i}\right)
$$

where $w_{i}$ : is the real wage by worker for sector $i$; vwrand $d_{i}$ : is a dummy variable that takes value 1 if the real wage has increased in sector $i$ with respect to the previous year and zero otherwise; pempd $d_{i}$ : is a dummy that takes value 1 if the number of workers in sector $i$ is greater than average; vempd $d_{i}$ : is a dummy that takes value 1 if the employment in sector $i$ has increased with respect to the previous year's employment.

The relationship between effort and real wages has to be positive in a efficiency wage model. In this context, firms pay above the marketclearing level to increase productivity. In our model, the wage does not 
clear the labour market: instead, we use the average wage paid by the group of sectors to which the ratio $(K / L)$ is similar. We consider that the average wage acts as a proxy of the opportunity wage of the sector's labour force.

Through $v w r a n d_{i}$ we try to identify the effect of an increase in the real wage with respect to the previous year. The efficiency wage model assumes that workers either compare themselves with others in a similar position, or with their expected opportunities if they left the sector. There is evidence that people become accustomed to a certain state, good or bad, and therefore tend to be influenced by events that are better or worse than normal. In this case, we test the hypothesis of the sociological model, and this dummy could peak the treatment of the sector: the relationship with the effort thus has to be positive.

With pempd $d_{i}$ we reflect the difficulties of monitoring when the number of workers is high. Because we do not have a direct measurement of this variable, we have to construct one which considers differences with respect to the average of workers for all the sectors in the group. We expect that, if the sector is above average, the relationship with effort will be negative, because in this case it is more difficult to control the work.

While differences in human capital may account for the positive influence of wages on productivity, it is less likely to explain why variations in unemployment would improve productivity. Thus, with $v e m p d_{i}$ we try to measure changes in employment with respect to the previous year. We do not have any unemployment in the SIE; consequently, we use this variable as a proxy for the effect of unemployment on the effort. In a efficiency wage model, the unemployment acts as a discipline device: if it increases, we also expect higher effort (keeping the wage constant), so with this dummy we expect a negative relationship with respect to effort.

We are interested in the sectors of the SIE which we think can pay wage premia. If some sectors do so, it is because they are interested in capturing effort through wage, and a labour-aumenting production function does exist. These sectors do not know the effort function of their labour force but, instead, they observe that an above average increase in the wage will increase the productivity of the labour, which will also be higher than average. To discriminate between the sectors that pay these wage premia and those that do not we made a rule with respect to average labour productivity. We suppose that the sectors with productivity above the group average will pay wage premia and those with one below average will not. Furthermore, we suppose that if the sectors do not have a labour-aumenting production function, e will be 
equal to one and expression [1] will become a standard production function. In this case, the sector will have an average labour productivity below the group average. The aim is to see whether differences in productivity can be explained by differences in wages. To this end, we censor the data, giving zeros to the sectors with negative differences compared to the average, and keeping the value of those with a positive difference.

Now we define the average product of the first group, $j$, as:

$$
(Y / L)_{j}^{*}=g\left[e_{j}^{*},(K / L)_{j}^{*}\right]
$$

where $(Y / L)_{j}^{*}$ is the mean of the average product of labour of group $j$, $e_{j}^{*}$ is the effort of group $j$, and $(K / L)_{j}^{*}$ is the mean of the stock of capital by worker for the same group.

We assume that the effort function of each group depends on the average wage paid by its group. Then we subtract [13] from [11] to obtain:

$$
(Y / L)_{i}-(Y / L)_{j}^{*}=g\left[e_{i},(K / L)_{i}\right]-g\left[e_{j}^{*},(K / L)_{j}^{*}\right]
$$

To estimate equation [14] we can suppose a Cobb-Douglas production function with constant returns to scale. The production function of group $i$ that belongs to group $j$ is thus:

$$
y_{i j}=A e_{i j}{ }^{\beta} L_{i j}{ }^{\beta} K_{i j}{ }^{1-\beta}
$$

whose average product of labour can be written as:

$$
y_{i j} / L_{i j}=A e_{i j}{ }^{\beta}\left[K_{i j} / L_{i j}\right)^{1-\beta}
$$

We assume the level of production of group $j$ can also be expressed throughout a Cobb-Douglas production function with the same characteristic as that of the sector. The average productivity of the labour force of the group $j$ is thus:

$$
y_{j} / L_{j}=A e_{j}^{\beta}\left[K_{j} / L_{j}\right]^{1-\beta}
$$

Subtracting [17] from [16], we obtain the difference between the average productivity of labour from the sector to the group, which is a function of the stock of capital by worker and the level of the effort:

$$
y_{i j} / L_{i j}-y_{j} / L_{j}=A e_{i j}^{\beta}\left[K_{i j} / L_{i j}\right]^{1-\beta}-A e_{j}^{\beta}\left[K_{j} / L_{j}\right]^{1-\beta}
$$

The groups have been built in a way that allows us to assume that the average stock of capital by worker is equal for the sector and for the group. We can thus write equation [18] as:

$$
y_{i j} / L_{i j}-y_{j} / L_{j}=A\left[K_{j} / L_{j}\right]^{1-\beta}\left[e_{i j}^{\beta}-e_{j}^{\beta}\right]
$$

To express the differences in productivity in differences in effort, we assume the labour factor has constant return in the short run $(\beta=1)$. 
With this assumption, we implicitly assume the average productivity of labour is homogeneous of degree one in effort, and the degree of homogeneity with respect to the $(K / L)$ ratio is zero. We can assume homogeneity of degree zero in $(K / L)$ because inside each group this ratio is equal for the entire sector.

Assuming both functions are homogeneous of degree one in effort and of degree zero in the stock of capital by worker, we can write [19] as:

$$
y_{i j} / L_{i j}-y_{j} / L_{j}=A\left[e_{i j}-e_{j}\right]
$$

We suppose the $g$ 's function linear in effort. In [20] the difference in productivity of one sector, for example $i$, and the average of its group, for example $j$, is thus related to the difference in the effort of the sector and that of the group.

It is also important to define the effort function that appears in equation [12]. We assume a linear function for the effort in the short run, which can be expressed as:

$$
e_{i j}=\alpha_{0}+\alpha_{1} w_{i j}+\alpha_{2} \text { vwrand }_{i j+a 3} \text { pempd }_{i j}+\alpha_{4} \text { vempd }_{i j}
$$

Substituting [21] in [20] and assuming the level of the effort of the group depends on the mean of the wage paid for all the sectors belonging to the same group, we obtain:

$$
\begin{aligned}
y_{i j} / L_{i j}-y_{j} / L_{j}= & \alpha_{0}+\alpha_{1} w_{i j}+\alpha_{2} v_{w r a n d}+\alpha_{3} \text { pempd }_{i j} \\
& +\alpha_{4} \text { vempd }_{i j}+\alpha_{5} w_{j}
\end{aligned}
$$

In equation [22] there could be an estimation bias for the existence of differences in the $(K / L)$ ratio among groups of sectors. To avoid this, we reinforce the estimation of equation [22] with another estimation where the sample is grouped by the second method, because in this case there are differences in the $(K / L)$ ratio between the sector and the group, even if small. With the introduction of the $(K / L)$ ratio, we can avoid an omitted variable possibility.

To allow for this possibility, we start taking logarithms of [16] and [17] and, after subtracting both expressions, we obtain:

$$
\begin{aligned}
\ln \left[y_{i j} / L_{i j}\right]-\ln \left[y_{j} / L_{j}\right)= & \beta\left[\ln e_{i j}-\ln e_{j}\right]+(1-\beta)\left[\ln \left(K_{i j} / L_{\mathrm{ij}}\right)\right. \\
& \left.-\ln \left(K_{j} / L_{j}\right)\right]
\end{aligned}
$$

The effort function used for the regression of [23] will be:

$$
e_{i j}=\exp \left(\alpha_{0}+\alpha_{1} w_{i j}+\alpha_{2} \text { vwrand }_{i j}+\alpha_{3} \text { pempd }_{i j}+\alpha_{4} \text { vempd }_{i j}\right)
$$


Equation [23] is more general and allows us to check whether the results obtained with this equation, for the second method, in the panel data regression are in line with that obtained with equation [22] for the first and second method used in the estimation of the double-hurdle model.

\subsection{The double-hurdle model}

Equation [22] will be used to censure the data and to estimate the double-hurdle model.

The advantage of the first method with respect to the second regards the difference between the ratio $(K / L)$ of the sector and the stock of capital of the group, which in the first case is small. On the other hand, its difficulty lies in the configuration of the groups because it is not the same for all the years. When we use the second method we lose high equality among the ratios $(K / L)$.

In general, the censure rule are the same for both methods. The difference is only in the mixture of sectors. In any case, we estimate the sample obtained in both cases.

Each model for any censored data source begins by specifying a latent regression model. Typically, this will describe the method specification in the absence of censoring. In our case, we follow the double-hurdle model from Cragg (1971), which can be expressed as:

$$
\begin{aligned}
& D_{i}^{*}=\left(\phi_{i}-\phi_{i}^{*}\right)=\alpha_{i}^{\prime} Z+\varepsilon_{i} \\
& {\left[\begin{array}{l}
\varepsilon_{i} \\
u_{i}
\end{array}\right] N(0, \Sigma)} \\
& \hat{e}_{i}=\beta^{\prime} X_{i}+u_{i}
\end{aligned}
$$

and, moreover:

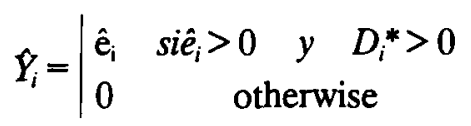

Here $\hat{Y} i$ picks up the right-hand side term of [22]; $\hat{e}_{i}$ is the difference between the effort in the sector and the effort of the group to belong to the sector; $\phi_{i}^{*}$ is the average value of the productivity by worker for the group of sectors with the same ratio $(K / L)$.

For sectors with a $\phi_{i}$ smaller than $\phi_{i}^{*}$ we suppose the sector does not capture an extra level of effort, and the value in the sample will be zero. In this context $D_{i}^{*}$ is an unobserved variable which determine whether or not that captioned of effort exists. The model proposed by Cragg is 
an extension of the Tobit model. In fact, if all the sectors can potentially pay wage premia, we are in the Tobit model.

\subsection{The panel data model}

The panel data estimation refers to cross-section data that has been pooled over time. Our panel is composed of 24 sectors with an average productivity of labour higher than the average of its group ${ }^{2}$ for all the period (1979-1988). In this case, we can follow the same sector through this decade. When we move from the single cross-section to panel data, the information improves.

If we introduce the time component in [23], we can write the fixed effect model as:

$$
\begin{aligned}
& y_{i t}{ }^{*}=\alpha_{i}+\beta^{\prime} X_{i t}+u_{i t} \\
& u_{i t}=\rho u_{i t-1}+\mu_{i t}
\end{aligned}
$$

The random effect model can be written as:

$$
\begin{aligned}
& y_{i t}^{*}=a+\beta^{\prime} X_{i t}+u_{i t}+\varepsilon_{i t} \\
& u_{i t}=\rho u_{i t-1}+\mu_{i t}
\end{aligned}
$$

where $y_{i t}{ }^{*}$ is the differences in productivity between the sector and the group, $X_{i t}$ is the set of explanatory variables that appear in [22], $\alpha_{i}$ is the unobservable specific effect of the sector, $u_{i i}$ is the disturbance term that follows an AR1 process, and $\varepsilon_{i t}$ is a random variable which contains the individual specific effects that are constant over time.

It is possible that we may observe a positive relationship between productivity and wages that is unrelated to that embodied in efficiency wage consideration. One reason may be a simultaneity bias. If workers share rents, for example in "insider-outsider" models of wage determination, high productivity in the firm will cause high relative wages. This is unlikely to be a problem when interpreting our results because we use an internal instrumental variable estimator to account for this difficulty. The computer program for panel data that allows for this possibility is by Manuel Arellano and Stephen Bond, and will be used for this estimation.

A second reason why the relationship between wages and productivity could be positive is the existence of differences in labour quality among sectors. The SIE has few variables that reflect labour quality, but all the sectors used in the regression have the same proportion of blue-collar workers and white-collar workers: the former are some eighty percent of the labour force of each sector. 
Another possibility is that these differences are not observable to the econometrician. We attempt to control for this by allowing for a firmspecific effect. Another reason why it is unlikely that the effects of relative wages on productivity are wholly attributable to unobserved skill differences is the fact that inter-industry wage differentials do not appear to be explicable in terms of standard human capital consideration. For example, Krueger and Summer (1986) show that workers who switch industries appear to acquire, on average, the wage premium attributable to their new industry.

A common practice is to estimate the first difference form to remove the fixed-effect component, and then carry out the estimation by using an instrumental variable program where the wage is taken to be endogenous. ${ }^{3}$

\section{Basic results}

Our basic results are reported in the tables of Appendix 1. We have estimated a Tobit, Probit and truncated model. Through a Probit, we can identify the significant variables which determine the likelihood that a sector pays a wage premium. In a Tobit model, we can also know the value of the parameter.

Cragg's specification allows the parameters in the implied probit ${ }^{4}$ equation to differ completely from those in the Tobit model if the complete model is a Probit model for $D$, and a separate truncated regression model for the positive values of $Y$.

The Tables 1, 2 and 3 correspond with the results obtained when we use the censored sample made with the sectors grouped by the first method.

By the second method, we group the sectors of the SIE following the NACE-CLIO classification reported in Table 4. We then make subgroups trying to get the small difference between the $(K / L)$ ratio from the sector and from the group. In Tables 5, 6 and 7 we show the cross-section results obtained by this method.

In Table 8 we estimate the existence of wage premia throughout panel data for the period (1979-88). In this case, the sample are the sectors, grouped by the second method, with an average labour productivity higher than the group average for the entire period 1979-1988.

As we can see in Table 1, the estimated parameters from the Tobit and Probit model are very similar. Also, the sign of all the parameters from one model are equal to the other. In the truncated model, the sign 
Table 1. Estimation for 1979

\begin{tabular}{lccc}
\hline Variables & Probit & Tobit & Truncated \\
\hline wrl & 5.1060 & 0.5614 & 1.2225 \\
& $(0.2475)$ & $(0.2475)$ & $(0.2433)$ \\
wrl2 & -0.8522 & -0.1474 & -0.3730 \\
& $(0.4319)$ & $(0.4319)$ & $(0.4561)$ \\
awrl & -3.9679 & -0.3848 & -0.9421 \\
& $(0.1660)$ & $(0.1660)$ & $(0.1733)$ \\
vempd & -0.3016 & -0.4003 & -0.1134 \\
& $(0.4214)$ & $(0.4214)$ & $(0.4671)$ \\
pempd & -0.3744 & -0.4316 & -0.1134 \\
& $(0.4791)$ & $(0.4791)$ & $(0.4671)$ \\
$\sigma$ & - & $0.8797 \mathrm{E}-01$ & 0.12993 \\
Log- $L$ & -42.55998 & 16.09127 & 61.42521
\end{tabular}

LRT: 5.548

Notes: Standard deviations in parentheses; Dependent variable for Tobit and Truncated dmper; Dependent variable for Probit $D$.

Table 2. Estimation for 1984

\begin{tabular}{lccc}
\hline Variables & Probit & Tobit & Truncated \\
\hline wrl & 9.1552 & 0.6314 & 0.1287 \\
& $(0.2927)$ & $(0.2927)$ & $(0.2942)$ \\
wrl2 & -1.8255 & $-0.9101 \mathrm{E}-01$ & -0.4377 \\
& $(0.5725)$ & $(0.5725)$ & $(0.6254)$ \\
awrl & -6.3559 & -0.4987 & -0.7628 \\
& $(0.2161)$ & $(0.2161)$ & $(0.2394)$ \\
vempd & -1.0817 & $-0.4305 \mathrm{E}-01$ & -0.2320 \\
& $(0.3790)$ & $(0.3790)$ & $(0.4568)$ \\
pempd & -0.3126 & $-0.4036 \mathrm{E}-01$ & -0.2088 \\
& $(0.4729)$ & $(0.4729)$ & $(0.4200)$ \\
vwrand & -0.3009 & $-0.3726 \mathrm{E}-01$ & $-0.9536 \mathrm{E}-01$ \\
& $(0.4279)$ & $(0.4279)$ & $(0.4709)$ \\
$\sigma$ & - & 0.10199 & 0.17685 \\
Log- $L$ & -34.52136 & 10.06348 & 48.95565 \\
LRT: 8.74 & & & \\
\hline
\end{tabular}

Notes: Same as for Table 1.

is similar to the Tobit and Probit models for all the variables. With this sample we could not regress the truncated model with the dummy vwrand because when we made the truncation we got a column of zeros. Thus we have not reported values for such a variable. 
Table 3. Estimation for 1988

\begin{tabular}{lccc}
\hline Variables & Probit & Tobit & Truncated \\
\hline wrl & 1.9341 & 0.2917 & 0.8916 \\
& $(0.3309)$ & $(0.3309)$ & $(0.3411)$ \\
wrl2 & 0.7219 & $0.4170 \mathrm{E}-02$ & -0.1370 \\
& $(0.6963)$ & $(0.6963)$ & $(0.7610)$ \\
awrl & -2.6609 & -0.2934 & -0.8862 \\
& $(0.2454)$ & $(0.2454)$ & $(0.2671)$ \\
vempd & $-0.9098 \mathrm{E}-01$ & $-0.1119 \mathrm{E}-01$ & $-0.3708 \mathrm{E}-01$ \\
& $(0.4997)$ & $(0.4997)$ & $(0.5021)$ \\
pempd & -0.2354 & $-0.3574 \mathrm{E}-01$ & -0.2450 \\
& $(0.4642)$ & $(0.4642)$ & $(0.4434)$ \\
vwrand & -0.6175 & $-0.5061 \mathrm{E}-01$ & -0.3024 \\
& $(0.3107)$ & $(0.3107)$ & $(0.1690)$ \\
$\sigma$ & - & $0.9510 \mathrm{E}-01$ & 0.13905 \\
Log- $L$ & -39.02429 & 13.42663 & 57.06257 \\
LRT: 9.22 & & & \\
\hline
\end{tabular}

Notes: Same as for Table 1.

Table 4. Sectoral equivalents for the industrial sectors

\begin{tabular}{lrcc}
\hline NACE-CLIO R(25) & E.I. & C.B. & CNAE (1974) \\
\hline 2. Metallic, mineral and steel industry & $9-11$ & $12,14,15$ & 21,22 \\
3. Minerals and products, no metallics & $12-18$ & $13,16,17,18,19$ & 21,22 \\
4. Chemical & 19,30 & 20,23 & 25 \\
5. Metallics products & $31-35$ & 24 & 31 \\
6. Machinery & 36,37 & $25,26^{*}$ & 32 \\
7. Office machibnery and others & 38,46 & 33 and 330 CNAE & $33-39$ \\
8. Electric materials & 39,40 & $27,35,38$ & 34,35 \\
9. Transport materials & $41-45$ & $29-32$ & $36-38$ \\
10. Food industry & $47-64$ & $35-39$ & 41,42 \\
11. Textile, clothing and shoes & $65-74$ & $40-42$ & $43-45$ \\
12. Paper and derived & $80-82$ & 44,45 & 47 \\
13. Couch and plastic & $83-84$ & 46 & 48 \\
14. Wood, cork and others & $75-79$ & 43,47 & 46,49 \\
& $85-89$ & & \\
\hline
\end{tabular}

*Except for 330 CNAE.

Source: Cesar Alonso.

In Table 2 the results for Tobit and Probit are similar but in this case the sign of the vempd in the truncated regression is different. In Table 3 the differences appear in vwrand and wrl2 for the truncated model.

The Likelihood Ratio Test (LRT) is included in each table. Since the Tobit log-likelihood is simply the sum of the Probit and truncated 
Table 5. Estimation for 1979

\begin{tabular}{lccc}
\hline Variables & Probit & Tobit & Truncated \\
\hline wrl & 5.1212 & 0.6111 & 1.1164 \\
& $(0.2611)$ & $(0.2611)$ & $(0.2501)$ \\
wrl 2 & 0.3304 & $-0.4165 \mathrm{E}-01$ & $-0.9679 \mathrm{E}-01$ \\
& $(0.4689)$ & $(0.4689)$ & $(0.4841)$ \\
awrl & -6.1327 & -0.6383 & -1.1753 \\
& $(0.2226)$ & $(0.2226)$ & $(0.2137)$ \\
vempd & 0.4444 & $-0.6013 \mathrm{E}-01$ & 0.1347 \\
& $(0.5030)$ & $(0.5030)$ & $(0.5039)$ \\
pempd & 0.3952 & $-0.1613 \mathrm{E}-01$ & $-0.2443 \mathrm{E}-01$ \\
& $(0.4990)$ & $(0.4990)$ & $(0.5039)$ \\
$\sigma$ & - & $0.7537 \mathrm{E}-01$ & $0.6484 \mathrm{E}-01$ \\
Log- $L$ & -41.90555 & 19.60443 & 68.97978 \\
LRT: $: 14.93$ & & & \\
\hline
\end{tabular}

Notes: Same as for Table 1.

Table 6. Estimation for 1984

\begin{tabular}{lccc}
\hline Variables & Probit & Tobit & Truncated \\
\hline wrl & 10.110 & 0.4806 & 0.3352 \\
& $(0.2937)$ & $(0.2937)$ & $(0.2759)$ \\
wrl2 & -0.8415 & $-0.1732 \mathrm{E}-01$ & 0.1605 \\
& $(0.5754)$ & $(0.5754)$ & $(0.5930)$ \\
awrl & -9.2659 & -0.4697 & -0.6458 \\
& $(0.2448)$ & $(0.2448)$ & $(0.2446)$ \\
vempd & 0.3276 & $-0.7180 \mathrm{E}-01$ & $-0.4345 \mathrm{E}-01$ \\
& $(0.3862)$ & $(0.3862)$ & $(0.3970)$ \\
pempd & -0.3491 & $-0.2214 \mathrm{E}-01$ & $-0.8285 \mathrm{E}-01$ \\
& $(0.4990)$ & $(0.4990)$ & $(0.4839)$ \\
vwrand & 0.2514 & $-0.1153 \mathrm{E}-01$ & $-0.2051 \mathrm{E}-01$ \\
& $(0.4320)$ & $(0.4320)$ & $(0.4502)$ \\
o & - & $0.7101 \mathrm{E}-01$ & 0.11602 \\
Log- $L$ & -32.46829 & 28.48045 & 64.63094 \\
LRT: 7.36 & & & \\
\hline
\end{tabular}

Notes: Same as for Table 1.

regression log-likelihoods, a simple test of the Tobit model as a restriction on Cragg's model $(\gamma=\beta / \sigma)$ can be based on: $2\left(\log -\mathscr{L}_{\text {PROBrT }}+\right.$ $\left.\log -\mathscr{L}_{\text {TRUNCATED }}-\log -\mathscr{L}_{\text {TOBrT }}\right)$; which will be distributed as a $\chi^{2}$ with as many degrees of freedom as the regression has explanatory variables. 
Table 7. Estimation for 1988

\begin{tabular}{lccc}
\hline Variables & Probit & Tobit & Truncated \\
\hline wrl & 5.7649 & 0.2392 & $0.6705 \mathrm{E}-01$ \\
& $(0.3443)$ & $(0.3443)$ & $(0.3455)$ \\
wrl & $0.4156 \mathrm{E}-01$ & $0.6235 \mathrm{E}-01$ & 0.1014 \\
& $(0.7403)$ & $(0.6963)$ & $(0.7968)$ \\
awrl & -6.2273 & -0.3387 & -0.1723 \\
& $(0.2917)$ & $(0.2917)$ & $(0.2974)$ \\
pempd & 0.2445 & $-0.346 \mathrm{E}-02$ & $-0.1888 \mathrm{E}-01$ \\
& $(0.4972)$ & $(0.4972)$ & $(0.4953)$ \\
wwrand & 0.3452 & $-0.2837 \mathrm{E}-01$ & $0.7063 \mathrm{E}-02$ \\
& $(0.3053)$ & $(0.3053)$ & $(0.2262)$ \\
$\sigma$ & - & $0.7187 \mathrm{E}-01$ & $0.6904 \mathrm{E}-01$ \\
Log-L & -37.13487 & 26.73926 & 67.19860 \\
LRT: 6.64 & & & \\
\hline
\end{tabular}

Notes: Same as for Table 1.

Table 8. Estimation of wage premia, 1979-1988

\begin{tabular}{lc}
\hline Variables & Inst. variable \\
\hline Constant & -0.119227 \\
dpmer $(-1)$ & $(-2.404)$ \\
& 0.084956 \\
wrl & $(0.5469)$ \\
& 0.834219 \\
awrl & $(3.2563)$ \\
& -1.350148 \\
vempd & $(-2.305)$ \\
& -0.002998 \\
vwrand & $(-0.171)$ \\
& 0.066807 \\
$T$ & $(1.9004)$ \\
AK & 0.008901 \\
& $(2.3261)$ \\
$K$ & -0.014926 \\
T.WALD & $(-0.395)$ \\
T.SARGAN & 0.206938 \\
\hline
\end{tabular}

Notes: $t$-student ratios in parentheses. Dependent variable dpmer. 
The values of the test are smaller than the critical value and thus we can conclude that the Tobit model is the appropriate one to estimate equation [22].

The sign of the variables wrl, awrl, vempd and pempd are as expected in an efficiency wage framework. On the other hand, the coefficient of the dummy variable vwrand has the opposite sign.

When we make the regression through the second method we observe that the sign of coefficients $w r l$ and awrl are equal to the previous estimation for the first method. The values of pempd are the opposite of that expected for 1979 and 1988. But in this case vwrand has the correct sign for 1984 and 1988.

In Table 8 , we report the results obtained by the regression through panel data. We use the model in first differences to eliminate the fixedeffect component. The Wald and Sargan tests also appear in this table because the DPD program computes them automatically. The Wald test is of joint significance for all the variables entered in $X$ (a test of the null hypothesis that their estimated coefficients are all zero), it is asymptotically distributed as $\chi^{2}$ with the degrees of freedom provided. The Sargan test is related to the validity of the instruments used in the estimation (in this case the null hypothesis is that the instruments and the error term are orthogonal). As we can see, both have the correct value.

Both variables $w r l$ and $a w r l$ are significantly different from zero, shown in the table. On the other hand, vempd and vwrand have the correct sign but we cannot reject the null hypothesis about the coefficient of the vempd variable, while vwrand appears significantly different from zero at $5 \%$ level of significance.

The coefficients of $A K$ and $K$ signify respectively the average stock of capital by worker for the group and the stock of capital by worker for the sector. The sign of these two variables are as expected in equation [23]: $A K$ is insignificantly different from zero, while $K$ is significant at $1 \%$ level.

Through the value of the coefficient $K$ we can obtain $\beta$, and then the elasticity of the effort with respect to $w r l, \alpha_{1}$ in equation [24]. The elasticity of the effort with respect to the wage is equal to 1.05 which means that Solow's condition is fulfilled.

Generally, the coefficients of the variables were as expected. The positive sign of the wage paid by the sector and the negative sign of the average wage of the group indicate that some sectors were paying wage premia in the period 1979-1988. In this sense, higher than average wages increase the average product of labour above the average. And by Solow's condition we can suggest that the wage paid by the sector is an equilibrium wage. 
The efficiency wage model can explain how the unemployment rate can affect the level of production in the short run. We could not obtain this data source for the sectors of our sample and thus made the dummy variable vempd.

The relationship between unemployment and effort has to be positive in a efficiency wage framework. We have shown that higher employment in the sector with respect to the previous year (vempd) is negative, which means that, keeping the wage constant, an increase in the rate of employment diminished the average productivity of labour; in other words, to obtain the same level of effort with higher employment the wage has to increase. This fact is illustrated in Figure 3.

The sign of $v$ wrand is positive, as expected in a sociological model. It is worth mentioning that there is some other evidence for the view that, if the efficiency wage model is valid, wages in a sector should only depend on outside wages and some other variables which influence the worker's effort function. Specifically, wages should not be influenced by insider variables like firm-specific demand or technological shocks. However, Nickell and Wadhwani (1989) report evidence suggesting that wages are influenced by such insider variables. This is not consistent with the standard efficiency wage models based on shirking, adverse

Figure 3. Effects on the effort function of an increase in the employment level

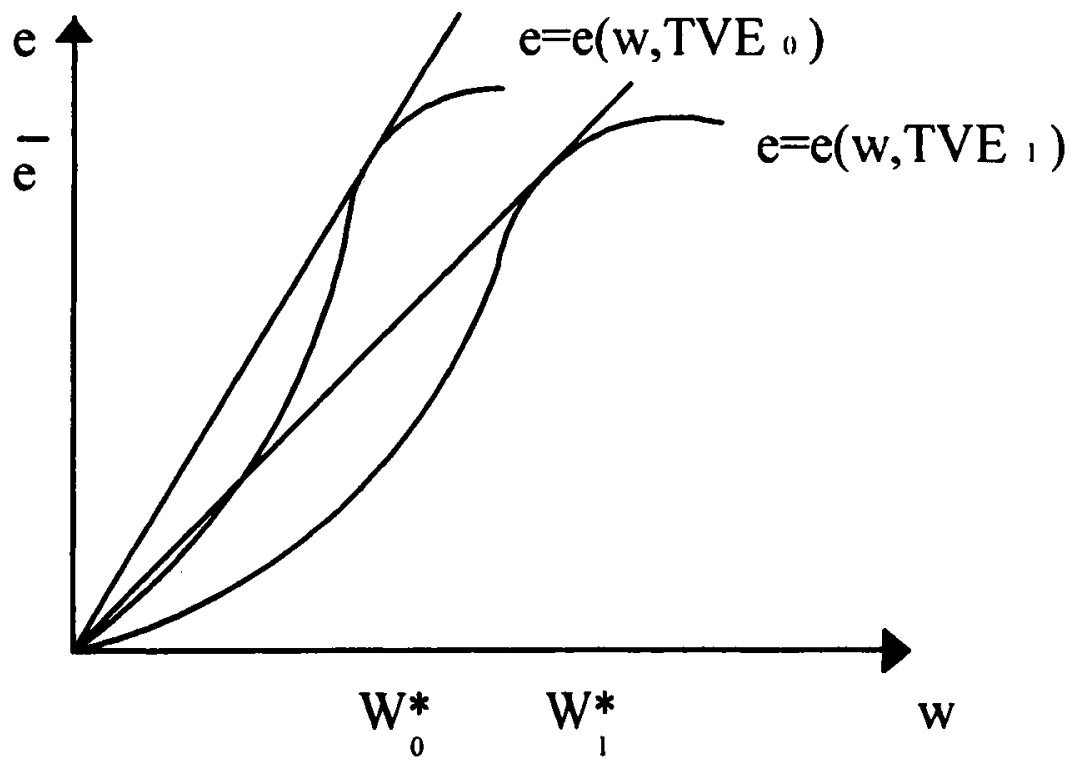


selection or turnover, although it may be consistent with the sociological model where workers only work effectively if they believe that the firm shares some of its profits with them.

The sign of pempd is negative, as corresponds with the predictions of the shirking model. When the number of workers is high in one sector, and consequently it is more difficult to monitor them on the job, it is easier for them to shirk instead of work. Thus, as the percentage of workers increases, the possibility of monitoring decreases and also clearly the average product of the labour.

\section{Conclusions}

We have found cross-section evidence for the existence of wage premia in the industrial sector of the Spanish economy. We have seen that average productivity of labour increases when either the relative wage or the level of unemployment rises. Moreover, there is support for the idea that an increase in the wage paid by the sector increases the average productivity of labour.

When we made the regression with panel data, the basic results obtained in the cross-section estimation remained. Thus, the difference between the wage paid by the sector and the average wage of the group again appear significant. This result is quite important if we think that any bargain made in one sector will affect all the sector's wages in the same group. Thus, if relative wages are important for productivity, any shock that can affect the high wage sector will produce employment adjustment instead of wages.

It is also possible to explain these results with other theories, for example the existence of unobserved human capital. However, it would be hard to explain the effect of unemployment on the average productivity of labour and it would be difficult to rationalize the positive effect of an increase in the sectoral wage on productivity, within a standard human capital framework.

\section{Data Appendix}

dpmer is the average product of labour by sector deviated from the mean of the average product of labour that we obtain for each group. For the construction of this variable we use the Industrial Index Price by sector published by INE, and the level of production by sector (before 
charging the indirect tax) published by the SIE. All the sector with productivity below average are substituted by zeros.

$D$ takes the value 1 if $d p m e r$ is strictly bigger than zero, and zero otherwise.

$K$ is the $K / L$ ratio of each sector.

$A K$ is the average $(K / L)$ ratio for each group of the sample grouped by the second method.

wrl is the real wage by worker (before deducting the direct taxes paid by workers) paid for each sector, deviated from the average wage for all the sectors. To obtain the real wage we use the Consumption Index Price.

$w r l 2$ is the squared real wage.

awrl is the average wage of each group.

vempd is constructed through the level of employment by sector in 1989 minus the employment in 1988 . We obtain the dummy variable of value 1 if the change in employment is positive, zero otherwise.

$v$ wrand is a dummy variable which takes the value 1 if the wage has increase in the sector, zero otherwise.

pempd is another dummy variable that takes value 1 if the number of workers in the sector is above the average of workers for all the sectors.

\section{Notes}

'In equilibrium, the elasticity of the effort with respect to the wage is equal to unity.

${ }^{2}$ The selection has been done by the second method.

${ }^{3}$ For further explanation, see Wadhwani and Wall (1988).

4 See Blundell (1990) for a good survey of this kind of model.

\section{References}

Akerlof G. A. (1982) "Labour Contracts as Partial Gift Exchange", Quarterly Journal of Economics 97: 543-569.

Akerlof G. A. and Yellen J. L. (1986) Efficiency Wage Models of the Labour Market, Cambridge University Press.

Arellano M. and Bond S. (1988) "Dynamic Panel Data Estimation Using DPD: A Guide for Users", Institute of Economics and Statistics.

Blundell R. (1 990) "Lectures in Microeconometrics", University College of London. 
Cragg J. (1971) "Some Statistical Models for Limited Dependent Variables with Application to the Demand for Durables Goods", Econometrica 39: 829-844.

Gibbons R. and Katz L. (1987) "Unmeasured Ability and Inter-Industry Wage differences", NBER.

Hsiao C. (1986) Analysis of Panel Data, Cambridge University Press.

Krueger A. and Summers L. H. (1986) "Efficiency Wages and Inter-Industry Wage Structure", Econometrica 56: 259-294.

Murphy K. and Topel R. (1 987) Unemployment, Risk and Earnings: Testing for Equalizing Wage Differences in the Labour Market, New York: Basil Blackwell.

Nickell S. J. and Wadhwani S. (1989) "Insider Forces of Wage Determination" WP 334, CLE, London School of Economics.

Shapiro C. and Stiglitz J. (1984) "Equilibrium Unemployment as a Worker Discipline Device", American Economic Review 74: 433-444.

Wadhwani S. and Wall M. (1991) "A Direct Test of the Efficiency Wage Model Using UK Micro-Data", Oxford Economic Papers 43: 529-548. 